Review

\title{
Controversies in the Mechanism of Total Parenteral Nutrition Induced Pathology
}

\author{
Jain Ajay Kumar ${ }^{1, *}$ and Jeffery H. Teckman ${ }^{1,2}$ \\ 1. Department of Pediatrics, St. Louis University School of Medicine, Cardinal Glennon Children's \\ Medical Center, SSM Cardinal Glennon Hospital 1465 South Grand Blvd., St. Louis, \\ MO 63104, USA; E-Mail: teckmanj@slu.edu \\ 2. Department of Biochemistry and Molecular Biology, Saint Louis University School of Medicine \\ * Author to whom correspondence should be addressed; Department of Pediatrics, Saint Louis \\ University, SSM Cardinal Glennon Hospital 1465 South Grand Blvd., St. Louis, MO 63104, USA; \\ E-Mail: ajain3@slu.edu.
}

Academic Editor: Sari Acra

Received: 03 June 2015 / Accepted: 14 July 2015 / Published: 31 July 2015

\begin{abstract}
Over 30,000 patients are permanently dependent on Total Parenteral Nutrition (TPN) for survival with several folds higher requiring TPN for a prolonged duration. Unfortunately, it can cause potentially fatal complications. TPN infusion results in impairment of gut mucosal integrity, enhanced inflammation, increased cytokine expression and trans-mucosal bacterial permeation. It also causes endotoxin associated down regulation of bile acid transporters and Parenteral Nutrition Associated Liver Disease (PNALD), which includes steatosis, disrupted glucose metabolism, disrupted lipid metabolism, cholestasis and liver failure. Despite multiple theories, its etiology and pathophysiology remains elusive and is likely multifactorial. An important cause for TPN related pathologies appears to be a disruption in the normal enterohepatic circulation due to a lack of feeding during such therapy. This is further validated by the fact that in clinical settings, once cholestasis sets in, its reversal occurs when a patient is receiving a major portion of calories enterally. There are several other postulated mechanisms including gut bacterial permeation predisposing to endotoxin associated down regulation of bile acid transporters. An additional potential mechanism includes toxicity of the TPN solution itself, such as lipid mediated hepatic toxicity. Prematurity, leading to a poor development of bile acid regulating nuclear receptors and transporters has also been implicated as a causative factor. This review presents the current controversies and research into mechanisms of TPN associated injury.
\end{abstract}


Keywords: liver; gut; neonatal; parenteral nutrition

\section{Introduction}

Although use of Total Parenteral Nutrition (TPN) is lifesaving, it is responsible for significant complications resulting in both morbidity and mortality [1-3]. TPN administration is known to cause the well-characterized Parenteral Nutrition Associated Liver Disease (PNALD), which includes liver steatosis, inflammation, fibrosis, cholestasis, associated glucose intolerance and dyslipidemia. Animal studies have shown that TPN administration is also associated with significant gut mucosal atrophy [4-7]. Unfortunately, there are no established ameliorative strategies for TPN associated pathology.

The mechanisms of TPN related injury are likely multifactorial [8] and remain a major research focus in gastroenterology and hepatology. This manuscript seeks to review the current evidence as it relates to the postulated mechanisms involved with TPN related pathology.

\section{Bile Acid Mediated Farnesoid X Receptor (FXR) Induction of FGF19}

In clinical settings, TPN related injury does not develop if enteral nutrition is provided. In fact, it is well established that once cholestasis sets in, its reversal occurs when a patient is receiving all or a majority of calories via the enteral route. A study reviewed 172 neonates on TPN and noted significant differences in the development of cholestasis based on the day enteral feeding was started [9].

Recent insights from cell culture and animal models show that enteral bile acids activate a nuclear receptor, Farnesoid X Receptor (FXR) in intestinal epithelial cells [10,11]. Such activation stimulates production of a growth factor, Fibroblast Growth Factor-19 (FGF19) and its delivery via the portal circulation to the liver [12,13]. FGF19 functions as a secretory signal to the liver, regulating bile acid synthesis via repression of CYP7A1 (Cholesterol 7 alpha-hydroxylase-rate limiting step) [14]. Additionally, in obese mice, intravenous FGF19 prevented or reversed diabetes, improved glycemic control, improved lipid control, reduced hepatic triglyceride levels and reduced hepatic steatosis [15-17]. It is thus predicted that hepatic bile acid synthesis, lipid and glucose metabolism is modulated via intestinal FXR signaling [18-20]. We have previously published significantly reduced FGF19 levels with TPN use. When animals on TPN were treated with an FXR agonist (Chenodeoxycholic Acid), there was elevation in FGF19 level [21].

Thus, based on current literature, it seems possible that PNALD result from an altered FXR-FGF19 signaling. It is particularly important to note that while, Ursodeoxycholic acid (UDCA) has been used in patients with PNALD with inconsistent results [22-24], unlike CDCA, UDCA has minimal activity for FXR [10,20].

\section{TGR5 and Glucagon Like Peptides}

Animal studies indicate that intestinal mucosal atrophy occurs upon TPN infusion, however the mechanisms remain unknown. Rodent studies show that feeding bile acids induces mucosal proliferation $[6,25]$. A rather interesting result from our recent publication indicates a robust gut growth 
and near normalization of such atrophy upon treatment with bile acid receptor agonists [21]. It has also been reported that there is a significantly enhanced expression of Glucagon Like Peptides (GLPs) with bile acid treatment in animal models [21]. Data suggests that the Glucagon Like Peptide-1 (GLP-1) regulates insulin, glucose homeostasis and hepatic steatosis [26]. GLP-1 is increasingly recognized as one of the key gut hormones responsible for enhancing the insulin response to nutrient ingestion a phenomenon known as the 'incretin effect' [27]. Glucagon Like Peptide-2 (GLP-2) is one of the most important, well-established, gut-trophic factors [25].

GLP-1 and GLP-2 secretion by enteroendocrine cells is under regulation of the bile acid activated G protein-coupled receptor TGR5 [28,29]. TGR5 is highly localized in crypts and is known to modulate gut trophic effects [30,31]. This leads to a thought provoking idea that a disrupted TGR5 signaling and thus decreased GLP levels during TPN administration could additionally contribute to TPN injury.

\section{Gut Microbiota, Inflammation and FXR, TGR5}

Hepatic steatosis, inflammation, fibrosis, glucose intolerance and dyslipidemia are noted with TPN liver injury [7,32]. Intriguingly these phenotypes overlap with Nonalcoholic steatohepatitis (NASH) [33,34].

New data from human and animal studies point to an increasing evidence of a cross talk between the gut and the liver; with modulation of disease pathology by the gut microbiota [35,36]. Though an average person has only a small percentage of body weight attributable to bacteria (approximately two to five pounds of live bacteria) [37], in real cell numbers we are about $90 \%$ bacterial and $10 \%$ human. [38] Additionally, the microbial genome exceeds the human genome by two orders of magnitude making us genetically $99 \%$ bacterial and $1 \%$ human $[38,39]$.

Indeed, some recent studies have shown significant changes in gut microbiota with evolving liver cirrhosis. An increased dysbiosis in the form of greater abundance of bacterial colonies of gram negative organisms like Bacteroidaceae and Enterobacteriaceae have been reported with advancing liver dysfunction and cirrhosis [40]. In rodent studies, cecal microbiota from ob/ob mice when introduced into germ free wild mice resulted in modest fat gain and increased food calorie extraction when compared to mice receiving gut microbiota from lean donors [41]. Methods to exogenously modify gut microbiota have also been tested with encouraging results. When adult patient with biopsy proven hepatic dysfunction were treated with a combination of orally administered Lactobacillus bulgaricus and Streptococcus thermophilus for three months, there was a significant decrease in ALT, AST and gamma glutamyl transferase (GGT) levels compared to controls [42].

Animal studies have demonstrated an increase in Bacteroidetes compared to Firmicutes in TPN infused animals and that colonization with Bacteroidetes leads to intestinal inflammation $[43,44]$. Such bacterial colonization can also result in increased intestinal permeability [45,46]. Increased bacterial infiltration across the gut causes endotoxin and cytokine mediated down regulation of bile acid transporters and ultimately hepatic injury [47-49]. Significantly higher Tumor Necrosis Factor (TNF) and Interleukin-6 (IL-6) levels have been noted in animals on TPN [50-52]. Multiple investigators have reported a decrease in inflammation induced liver injury in rats upon initiation of oral antibiotics, suggesting a role of bacteria in the development or exacerbation of PNALD [53-55]. 


\section{FXR and TGR5 Regulated Gut Integrity}

Emerging data points to a gut protective role of FXR agonists. Mice lacking FXR have been shown to have increased ileal levels of bacteria and a compromised epithelial barrier and it has been implicated that FXR agonists may prevent epithelial deterioration and bacterial translocation [56,57].

Recent data from experimental colitis, implicates modulation of the intestinal barrier and immune responses by TGR5, postulating the noted effects being secondary to a change in the gut microbiota [58].

One of the most notable FXR modulated gene is inducible nitric oxide synthase (iNOS) [56,59]. Other FXR regulated genes include those coding for angiogenin (ANG1), a part of the acute phase response to infection, which has potent antibacterial actions. Carbonic anhydrase 12 (CAR12), involved in antibacterial defense by regulating luminal $\mathrm{pH}$ and ion balance is also modulated by FXR $[60,61]$. TGR5 activation is known to lower pro-inflammatory cytokines interleukin-1 $\alpha$ (IL-1 $\alpha$ ), IL-1 $\beta$, IL-6 and tumor necrosis factor- $\alpha(\mathrm{TNF}-\alpha)[62]$.

Therefore it remains plausible that a dysbiotic clonal expansion during TPN therapy causes increased gut permeability and hence endotoxin, cytokine mediated injury, which could be potentially prevented by FXR and TGR5 agonists.

\section{Role of the Lipid Emulsion}

The exact mechanisms of lipid induced liver injury remain poorly understood. Due to their rich content of essential fatty acids, traditionally, vegetable oils have been used as a source of lipids during parenteral nutrition. The primary source for lipids thus has been soybean oil derivatives [63]. As opposed to the soybean derived emulsions, with a predominance of $\omega$-6fatty acids, fish oil based emulsions are higher is $\omega$-3fatty acids [64]. Several studies have shown beneficial metabolic effects of $\omega$-3fatty acid based lipid solutions in preventing or attenuating hepatic steatosis and cholestasis $[65,66]$. A study in neonatal piglets compared hepatic outcomes when using parenteral nutrition containing a $100 \%$ soy based emulsion ( $\omega-6: \omega-3$ PUFA: 7:1) or a mixed lipid emulsion containing soy oil, medium-chain triglycerides (MCTs), olive oil, and fish oil ( $\omega-6: \omega-3$ PUFA: approximately 2.5:1). Prevention of liver disease and a reduction in systemic inflammation was noted with the higher $\omega$-3 based formulation [67].

In another study using neonatal piglets assessing if fish oil based lipid formulations could prevent PNALD, animals were given parenteral nutrition containing 100\% soybean oil, 100\% fish oil or a lipid mixture (soy oil, MCTs, olive and fish oil). After 14 days of treatment plasma levels of direct bilirubin, GGT and bile acids were significantly lower in animals receiving fish oil based emulsions with a greater reduction in direct bilirubin in animals on $100 \%$ fish oil [68].

Data from human studies using fish oil based emulsions have also been encouraging. Significant reduction in mortality and the need for liver transplantation has been noted in pediatric patients receiving fish oil based emulsions in comparison to those given plant derived emulsions $[69,70]$.

While there have been concerns for essential fatty acid deficiency with $100 \%$ fish oil based emulsions, recent studies have shown otherwise [71,72]. There is emerging data that indicates that fish oil based monotherapy results in platelet dysfunction [73], which may be of clinical relevance in the context of human TPN administration with such emulsions. Additionally, a recent publication suggests 
that improvement noted with a commercial $\omega$-3 based emulsion may be due to significantly higher levels of Vitamin E, however further studies elucidating mechanistic links may be needed [74].

High $\omega$-6fatty acid based emulsions are known to impact immune function by increasing cytokine production by activating the nuclear factor-kB pathway, which disrupts hepatobiliary transport leading to cholestasis [75]. Additionally high $\omega$-6fatty acids accentuate lipid perioxidation and deplete levels of anti-oxidant tocopherols [70,76]. Prospective studies have noted improvement in systemic inflammation, as well as improvement in parenteral nutrition associated liver disease with use of fish oil based lipids [67,77].

There is also emerging evidence of the inhibitory effects of phytosterols found in soy-based lipids on bile acid secretion and excretion. Preterm infants on soy based lipid emulsions have significantly higher levels of phytosterols compared to controls and poorly developed mechanisms eliminating phytosterols have been implicated in their vulnerability to PNALD [78]. It has been postulated that phytosterols augment hepatic inflammation through TLR4 (Toll Like Recptor 4) macrophage activation. Addition of stigmasterol (a phytosterol) to PN solutions has been associated with proinflammatory hepatic macrophage activation [79,80]. Phytosterols also exert an inhibitory effect on FXR [81-84] In fact stigmasterol antagonizes the bile acid activated FXR target genes Bile salt export pump (BSEP) and the orphan nuclear receptor Short heterodimer partner (SHP) in FXR $+/+$ mice but fails to do so in FXR -/- mice hepatocytes [82]. The disrupted FXR signaling secondary to phytosterols has been additionally implicated in the metabolic dysregulation of bile acid pathways contributing to hepatic injury.

There have also been studies evaluating the role of the amount of the lipid provided as a contributor to PNALD. Though traditionally lipids have been provided at $2-3$ grams $/ \mathrm{kg} / \mathrm{day}$, there have been studies demonstrating a reduction in the incidence of PNALD with a lipid dosed at $\leq 1 \mathrm{gram} / \mathrm{kg} / \mathrm{day}[85,86]$. Though this strategy has merits, there have been concerns for deleterious effects due to a lack of lipids in the growing infant. A higher Triene:Tetraene ratio has been noted in infants on lipid restricted parenteral nutrition indicating a trend towards a deficiency of essential fatty acids $[85,87,88]$.

\section{Toxicity of TPN Solution}

Data suggests that toxicity as well as relative deficiencies of parenteral nutrition components can lead to TPN associated injury. Aluminum, chromium and manganese have all been implicated. Aluminum present in the TPN solution is known to cause metabolic bone disease as well as neurological impairment [89]. In infant studies plasma concentration of aluminum has been shown to be several fold higher in patients receiving TPN vs. those on enteral nutrition [90].

Concerns have also been raised for organ damage secondary to chromium delivery during parenteral nutrition. Chromium plays a role in regulation of the action of insulin. Additionally, peripheral neuropathy, weight loss as well as kidney damage have been reported in patients receiving TPN. Over the past several years there has been an effort to decrease chromium concentration in parenteral nutrition solutions [91].

Anemia, cholestasis as well as neurotoxicity have been noted with manganese provided as part of TPN. Recent guidelines recommend monitoring of manganese levels if TPN has been provided for longer than 30 days. However, controversy exists in the method for assessing manganese stores as a 
biomarker of manganese associated toxicity. Whole blood levels of manganese are highly variable and do not stringently correlate with manganese toxicity [92]. Reduction in manganese levels in TPN solution has been shown to reduce intra organ manganese deposition and thus may help in preventing toxicity [93].

Diets with carbohydrate excess have also been noted to enhance liver injury during parenteral nutrition [94]. Even though dextrose is not considered directly hepatotoxic, it has been speculated that there is enhanced insulin release and a resulting upregulation of enzymes regulating fatty acid synthesis with excessive carbohydrates. This causes hepatic steatosis leading to inflammatory hepatic damage [95-97].

\section{Prematurity}

Clinical evidence points to significantly higher incidence of TPN associated pathology in premature babies in comparison to older individuals [98]. The mechanistic basis for such differences are not clearly delineated, however, it is postulated that immaturity in bile acid transporters regulating entero-hepatic circulation may be key contributors [99]. The expression of multidrug resistance protein 3, which is involved in phospholipid excretion in bile, was significantly less in human fetal livers in comparison to adult livers. The study also found significantly reduced levels of the Sodium/bile acid co-transporter protein, which is a key glycoprotein involved in normal entero-hepatic circulation [100-102]. Additionally, the expression of BSEP, which modulates the rate-limiting step of bile salt transport driving the enterohepatic circulation, though noted in early gestation, gradually increases with gestation age [101,102].

\section{Conclusions}

TPN infusion is associated with significant morbidity and mortality. Though several postulated mechanism have been noted and extensively researched, there appears to be a broad support for the hypothesis that TPN associated pathology results from an alteration of the normal enterohepatic circulation. Several other mechanisms as detailed in this review are likely contributors to varying degrees.

\section{Author Contributions}

Ajay Kumar Jain contributed to the design and interpretation of data for this manuscript as well as drafting the work and revising it critically for intellectual content. Jeffery H. Teckman contributed to critically revising the work for intellectual content. All authors agree to be fully accountable for ensuring the integrity and accuracy of the work and read and approved the final manuscript.

\section{Conflicts of Interest}

The authors declare no conflict of interest 


\section{References}

1. Rager, R.; Finegold, M.J. Cholestasis in immature newborn infants: Is parenteral alimentation responsible? J. Pediatr. 1975, 86, 264-269.

2. Kumpf, V.J. Parenteral nutrition-associated liver disease in adult and pediatric patients. Nutr. Clin. Pract. 2006, 21, 279-290.

3. Tomar, B.S. Hepatobiliary abnormalities and parenteral nutrition. Indian J. Pediatr. 2000, 67, 695-701.

4. Kubota, A.; Yonekura, T.; Hoki, M.; Oyanagi, H.; Kawahara. H.; Yagi, M.; Imura, K.; Iiboshi, Y.; Wasa, K.; Kamata, S.; et al. Total parenteral nutrition-associated intrahepatic cholestasis in infants: 25 years' experience. J. Pediatr. Surg. 2000, 35, 1049-1051.

5. Niinikoski, H.; Stoll, B.; Guan, X.; Kansagra, K.; Lambert, B.D.; Stephens, J.; Hartmann, B.; Holst, J.J.; Burrin, D.G. Onset of small intestinal atrophy is associated with reduced intestinal blood flow in TPN-fed neonatal piglets. J. Nutr. 2004, 134, 1467-1474.

6. Ekelund, M.; Kristensson, E.; Ekelund, M.; Ekblad, E. Total parenteral nutrition causes circumferential intestinal atrophy, remodeling of the intestinal wall, and redistribution of eosinophils in the rat gastrointestinal tract. Dig. Dis. Sci. 2007, 52, 1833-1839.

7. Kelly, D.A. Preventing parenteral nutrition liver disease. Early Hum. Dev. 2010, 86, 683-687.

8. Carter, B.A.; Shulman, R.J. Mechanisms of disease: Update on the molecular etiology and fundamentals of parenteral nutrition associated cholestasis. Nat. Clin. Pract. Gastroenterol. Hepatol. 2007, 4, 277-287.

9. Javid, P.J.; Collier, S.; Richardson, D.; Iglesias, J.; Gura, K.; Lo, C.; Kim, H.B.; Duggan, C.P.; Jaksic, T. The role of enteral nutrition in the reversal of parenteral nutrition-associated liver dysfunction in infants. J. Pediatr. Surg. 2005, 40, 1015-1018.

10. Makishima, M.; Okamoto, A.Y.; Repa, J.J.; Tu, H.; Learned, R.M.; Luk, A.; Hull, M.V.; Lustig, K.D.; Mangelsdorf, D.J.; Shan, B. Identification of a nuclear receptor for bile acids. Science 1999, 284, 1362-1365.

11. Claudel, T.; Staels, B.; Kuipers, F. The Farnesoid X receptor: A molecular link between bile acid and lipid and glucose metabolism. Arterioscler. Thromb. Vasc. Boil. 2005, 25, 2020-2030.

12. Inagaki, T.; Choi, M.; Moschetta, A.; Peng, L.; Cummins, C.L.; McDonald, J.G.; Luo, G.; Jones, S.A.; Goodwin, B.; Richardson, J.A.; et al. Fibroblast growth factor 15 functions as an enterohepatic signal to regulate bile acid homeostasis. Cell Metab. 2005, 2, 217-225.

13. Wang, L.; Lee, Y.K.; Bundman, D.; Han, Y.; Thevananther, S.; Kim, C.S.; Chua, S.S.; Wei, P.; Heyman, R.A.; Karin, M.; et al. Redundant pathways for negative feedback regulation of bile acid production. Dev. Cell 2002, 2, 721-231.

14. Li, J.; Pircher, P.C.; Schulman, I.G.; Westin, S.K. Regulation of complement C3 expression by the bile acid receptor FXR. J. Boil. Chem. 2005, 280, 7427-7434.

15. Tomlinson, E.; Fu, L.; John, L.; Hultgren, B.; Huang, X.; Renz, M.; Stephan, J.P.; Tsai, S.P.; Powell-Braxton, L.; French, D.; et al. Transgenic mice expressing human fibroblast growth factor-19 display increased metabolic rate and decreased adiposity. Endocrinology 2002, 143, $1741-1747$. 
16. Fu, L.; John, L.M.; Adams, S.H.; Yu, X.X.; Tomlinson, E.; Renz, M.; Williams, P.M.; Soriano, R.; Corpuz, R.; Moffat, B.; et al. Fibroblast growth factor 19 increases metabolic rate and reverses dietary and leptin-deficient diabetes. Endocrinology 2004, 145, 2594-2603.

17. Huang, X.; Yang, C.; Luo, Y.; Jin, C.; Wang, F.; McKeehan, W.L. FGFR4 prevents hyperlipidemia and insulin resistance but underlies high-fat diet induced fatty liver. Diabetes 2007, 56, 2501-2510.

18. Galman, C.; Arvidsson, I.; Angelin, B.; Rudling, M. Monitoring hepatic cholesterol 7alpha-hydroxylase activity by assay of the stable bile acid intermediate 7alpha-hydroxy-4cholesten-3-one in peripheral blood. J. Lipid Res. 2003, 44, 859-866.

19. Lu, T.T.; Makishima, M.; Repa, J.J.; Schoonjans, K.; Kerr, T.A.; Auwerx, J.; Mangelsdorf, D.J. Molecular basis for feedback regulation of bile acid synthesis by nuclear receptors. Mol. Cell 2000, 6, 507-515.

20. Parks, D.J.; Blanchard, S.G.; Bledsoe, R.K.; Chandra, G.; Consler, T.G.; Kliewer, S.A.; Stimmel, J.B.; Willson, T.M.; Zavacki, A.M.; Moore, D.D.; et al. Bile acids: Natural ligands for an orphan nuclear receptor. Science 1999, 284, 1365-1368.

21. Jain, A.K.; Stoll, B.; Burrin, D.G.; Holst, J.J.; Moore, D.D. Enteral bile acid treatment improves parenteral nutrition-related liver disease and intestinal mucosal atrophy in neonatal pigs. Am. J. Physiol. Gastrointest. Liver Physiol. 2012, 302, G218-G224.

22. Wales, P.W.; Allen, N.; Worthington, P.; George, D.; Compher, C.; Teitelbaum, D. A.S.P.E.N. Clinical Guidelines: Support of Pediatric Patients With Intestinal Failure at Risk of Parenteral Nutrition-Associated Liver Disease. JPEN J. Parenter. Enter. Nutr. 2014, 38, 538-557.

23. San Luis, V.A.; Btaiche, I.F. Ursodiol in patients with parenteral nutrition-associated cholestasis. Ann. Pharmacother. 2007, 41, 1867-1872.

24. Heubi, J.E.; Wiechmann, D.A.; Creutzinger, V.; Setchell, K.D.; Squires, R. Jr.; Couser, R.; Rhodes, P. Tauroursodeoxycholic acid (TUDCA) in the prevention of total parenteral nutrition-associated liver disease. J. Pediatr. 2002, 141, 237-242.

25. Burrin, D.; Stoll, B.; Moore, D. Digestive physiology of the pig symposium: Intestinal bile acid sensing is linked to key endocrine and metabolic signaling pathways. J. Anim. Sci. 2013, 91, 1991-2000.

26. Kohli, R.; Bradley, D.; Setchell, K.D.; Eagon, J.C.; Abumrad, N.; Klein, S. Weight loss induced by Roux-en-Y gastric bypass but not laparoscopic adjustable gastric banding increases circulating bile acids. J. Clin. Endocrinol. Metab. 2013, 98, E708-E712.

27. Drucker, D.J. The role of gut hormones in glucose homeostasis. J. Clin. Investing. 2007, 117, $24-32$.

28. Martinez-Augustin, O.; de Medina, F.S. Intestinal bile acid physiology and pathophysiology. World J. Gastroenterol. 2008, 14, 5630-5640.

29. Boesjes, M.; Brufau, G. Metabolic effects of bile acids in the gut in health and disease. Curr. Med. Chem. 2014, 21, 2822-2829.

30. Yasuda, H.; Hirata, S.; Inoue, K.; Mashima, H.; Ohnishi, H.; Yoshiba, M. Involvement of membrane-type bile acid receptor M-BAR/TGR5 in bile acid-induced activation of epidermal growth factor receptor and mitogen-activated protein kinases in gastric carcinoma cells. Biochem. Biophys. Res. Commun. 2007, 354, 154-159. 
31. Pellicciari, R.; Sato, H.; Gioiello, A.; Costantino, G.; Macchiarulo, A.; Sadeghpour, B.M.; Giorgi, G.; Schoonjans, K.; Auwerx, J. Nongenomic actions of bile acids. Synthesis and preliminary characterization of 23- and 6,23-alkyl-substituted bile acid derivatives as selective modulators for the G-protein coupled receptor TGR5. J. Med. Chem. 2007, 50, 4265-4268.

32. Buchman, A. Total parenteral nutrition-associated liver disease. JPEN J. Parenter. Enter. Nutr. 2002, 26, S43-S48.

33. Brunt, E.M.; Tiniakos, D.G. Histopathology of nonalcoholic fatty liver disease. World J. Gastroenterol. 2010, 16, 5286-5296.

34. Singer, C.; Stancu, P.; Cosoveanu, S.; Botu, A. Non-alcoholic Fatty liver disease in children. Curr. Health Sci. J. 2014, 40, 170-176.

35. Ferolla, S.M.; Armiliato, GN.; Couto, C.A.; Ferrari, T.C. The role of intestinal bacteria overgrowth in obesity-related nonalcoholic fatty liver disease. Nutrients 2014, 6, 5583-5599.

36. Hodin, C.M.; Visschers, R.G.; Rensen, S.S.; Boonen, B.; Olde Damink, S.W.; Lenaerts, K.; Buurman, W.A. Total parenteral nutrition induces a shift in the Firmicutes to Bacteroidetes ratio in association with Paneth cell activation in rats. J. Nutr. 2012, 142, 2141-2147.

37. Wexler, H.M. Bacteroides: The good, the bad, and the nitty-gritty. Clin. Microbial. Rev. 2007, 20, 593-621.

38. Xu, J.; Gordon, J.I. Honor thy Symbionts. Proc. Natl. Acad. Sci. U.S.A. 2003, 100, 10452-10459.

39. Sonnenburg, J.L.; Angenent, L.T.; Gordon, J.I. Getting a grip on things: How do communities of bacterial symbionts become established in our intestine? Nat. Immunol. 2004, 5, 569-573.

40. Bajaj, J.S.; Heuman, D.M.; Hylemon, P.B.; Sanyal, A.J.; White, M.B.; Monteith, P.; Noble, N.A.; Unser, A.B.; Daita, K.; Fisher, A.R.; et al. Altered profile of human gut microbiome is associated with cirrhosis and its complications. J. Hepatol. 2014, 60, 940-947.

41. Turnbaugh, P.J.; Ley, R.E.; Mahowald, M.A.; Magrini, V.; Mardis, E.R.; Gordon, J.I. An obesity-associated gut microbiome with increased capacity for energy harvest. Nature 2006, 444, 1027-1031.

42. Aller, R.; De Luis, D.A.; Izaola, O.; Conde, R.; Gonzalez Sagrado, M.; Primo, D.; De La Fuente, B.; Gonzalez, J. Effect of a probiotic on liver aminotransferases in nonalcoholic fatty liver disease patients: A double blind randomized clinical trial. Eur. Rev. med. Pharmacol. Sci. 2011, 15, 1090-1095.

43. Wu, S.; Powell, J.; Mathioudakis, N.; Kane, S.; Fernandez, E.; Sears, C.L. Bacteroides fragilis enterotoxin induces intestinal epithelial cell secretion of interleukin- 8 through mitogen-activated protein kinases and a tyrosine kinase-regulated nuclear factor-kappaB pathway. Infect. Immune. 2004, 72, 5832-5839.

44. Yoon, Y.M.; Lee, J.Y.; Yoo, D.; Sim, Y.S.; Kim, Y.J.; Oh, Y.K.; Kang, J.S.; Kim, S.; Kim, J.S; Kim, J.M. Bacteroides fragilis enterotoxin induces human beta-defensin-2 expression in intestinal epithelial cells via a mitogen-activated protein kinase/I kappaB kinase/NF-kappaB-dependent pathway. Infect. Immun. 2010, 78, 2024-2033.

45. Remacle, A.G.; Shiryaev, S.A.; Strongin, A.Y. Distinct interactions with cellular E-cadherin of the two virulent metalloproteinases encoded by a Bacteroides fragilis pathogenicity island. PloS ONE 2014, 9, e113896. 
46. Wu, S.; Lim, K.C.; Huang, J.; Saidi, R.F.; Sears, C.L. Bacteroides fragilis enterotoxin cleaves the zonula adherens protein, E-cadherin. Proc. Natl. Acad. Sci. U.S.A. 1998, 95, 14979-14984.

47. Green, R.M.; Beier, D.; Gollan, J.L. Regulation of hepatocyte bile salt transporters by endotoxin and inflammatory cytokines in rodents. Gastroenterology 1996, 111, 193-198.

48. Alrefai, W.A.; Gill, R.K. Bile acid transporters: Structure, function, regulation and pathophysiological implications. Pharm. Res. 2007, 24, 1803-1823.

49. Trauner, M.; Arrese, M.; Lee, H.; Boyer, J.L.; Karpen, S.J. Endotoxin downregulates rat hepatic ntcp gene expression via decreased activity of critical transcription factors. J. Clin. Invest. 1998, $101,2092-2100$.

50. Whiting, J.F.; Green, R.M.; Rosenbluth, A.B.; Gollan, J.L. Tumor necrosis factor-alpha decreases hepatocyte bile salt uptake and mediates endotoxin-induced cholestasis. Hepatology 1995, 22, 1273-1278.

51. Zheng, Y.J.; Tam, Y.K.; Coutts, R.T. Endotoxin and cytokine released during parenteral nutrition. JPEN J. Parenter. Enter. Nutr. 2004, 28, 163-168.

52. Lehmann, G.L.; Carreras, F.I.; Soria, L.R.; Gradilone, S.A.; Marinelli, R.A. LPS induces the TNF-alpha-mediated downregulation of rat liver aquaporin-8: Role in sepsis-associated cholestasis. Am. J. Physiol. Gastrointest.Liver Physiol. 2008, 294, G567-G575.

53. Lichtman, S.N.; Keku, J.; Schwab, J.H.; Sartor, R.B. Hepatic injury associated with small bowel bacterial overgrowth in rats is prevented by metronidazole and tetracycline. Gastroenterology 1991, 100, 513-519.

54. Freund, H.R.; Muggia-Sullam, M.; LaFrance, R.; Enrione, E.B.; Popp, M.B.; Bjornson, H.S. A possible beneficial effect of metronidazole in reducing TPN-associated liver function derangements. J. Surg. Res. 1985, 38, 356-363.

55. Koga, H.; Sakisaka, S.; Yoshitake, M.; Koga, H.; Sakisaka, S.; Yoshitake, M.; Harada, M.; Kumemura, H.; Hanada, S.; Taniguchi, E.; et al. Abnormal accumulation in lipopolysaccharide in biliary epithelial cells of rats with self-filling blind loop. Int. J. Mol. Med. 2002, 9, 621-626.

56. Inagaki, T.; Moschetta, A.; Lee, Y.K.; Peng, L.; Zhao, G.; Downes, M.; Yu, R.T.; Shelton, J.M.; Richardson, J.A.; Repa, J.J.; et al. Regulation of antibacterial defense in the small intestine by the nuclear bile acid receptor. Proc. Natl. Acad. Sci. U.S.A. 2006, 103, 3920-3925.

57. Verbeke, L.; Farre, R.; Verbinnen, B.; Covens, K.; Vanuytsel, T.; Verhaegen, J.; Komuta, M.; Roskams, T.; Chatterjee, S.; Annaert, P.; et al. The FXR agonist obeticholic acid prevents gut barrier dysfunction and bacterial translocation in cholestatic rats. Am. J. Pathol. 2015, 185, 409-419.

58. Cipriani, S.; Mencarelli, A.; Chini, M.G.; Cipriani, S.; Mencarelli, A.; Chini, M.G.; Distrutti, E.; Renga, B.; Bifulco, G.; Baldelli, F.; et al. The bile acid receptor GPBAR-1 (TGR5) modulates integrity of intestinal barrier and immune response to experimental colitis. PloS ONE 2011, 6, e25637.

59. Wallace, J.L.; Miller, M.J. Nitric oxide in mucosal defense: A little goes a long way. Gastroenterology 2000, 119, 512-520.

60. Hooper, L.V.; Stappenbeck, T.S.; Hong, C.V.; Gordon, J.I. Angiogenins: A new class of microbicidal proteins involved in innate immunity. Nat. Immunol. 2003, 4, 269-273.

61. Biet, F.; Locht, C.; Kremer, L. Immunoregulatory functions of interleukin 18 and its role in defense against bacterial pathogens. J. Mol. Med. 2002, 80, 147-162. 
62. Keitel, V.; Donner, M.; Winandy, S.; Kubitz, R.; Haussinger, D. Expression and function of the bile acid receptor TGR5 in Kupffer cells. Biochem. Biophys. Res. Commun. 2008, 372, 78-84.

63. Wanten, G.J.; Calder, P.C. Immune modulation by parenteral lipid emulsions. Am. J. Clin. Nutr. 2007, 85, 1171-1184.

64. Calder, P.C.; Jensen, G,L.; Koletzko, B.V.; Singer, P.; Wanten, G.J. Lipid emulsions in parenteral nutrition of intensive care patients: Current thinking and future directions. Intensive Care Med. 2010, 36, 735-749.

65. Bharadwaj, S.; Gohel, T.; Deen, O.J.; DeChicco, R.; Shatnawei, A. Fish oil-based lipid emulsion: Current updates on a promising novel therapy for the management of parenteral nutrition-associated liver disease. Gastroenterol. Rep. 2015, 3, 110-114.

66. Burns, D.L.; Gill, B.M. Reversal of parenteral nutrition-associated liver disease with a fish oil-based lipid emulsion (Omegaven) in an adult dependent on home parenteral nutrition. JPEN J. Parenter. Enter. Nutr. 2013, 37, 274-280.

67. Turner, J.M.; Josephson, J.; Field, C.J.; Wizzard, P.R.; Ball, R.O.; Pencharz, P.B.; Wales, P.W. Liver Disease, Systemic Inflammation, and Growth Using a Mixed Parenteral Lipid Emulsion, Containing Soybean Oil, Fish Oil, and Medium Chain Triglycerides, Compared With Soybean Oil in Parenteral Nutrition-Fed Neonatal Piglets. JPEN J. Parenter. Enter. Nutr. 2015, doi:10.1177/0148607115579711.

68. Vlaardingerbroek, H.; Ng, K.; Stoll, B.; Benight, N.; Chacko, S.; Kluijtmans, L.A.; Kulik, W. Squires, E.J.; Olutoye, O.; Schady, D.; et al. New generation lipid emulsions prevent PNALD in chronic parenterally fed preterm pigs. J. Lipid Res. 2014, 55, 466-477.

69. Puder, M.; Valim, C.; Meisel, J.A.; Le, H.D.; de Meijer, V.E.; Robinson, E.M.; Zhou, J.; Duggan, C.; Gura, K.M. Parenteral fish oil improves outcomes in patients with parenteral nutrition-associated liver injury. Ann. Sur. 2009, 250, 395-402.

70. Gura, K.M.; Lee, S.; Valim, C.; Zhou, J.; Kim, S.; Modi, B.P.; Arsenault, D.A.; Strijbosch, R.A.; Lopes, S.; Duggan, C. Safety and efficacy of a fish-oil-based fat emulsion in the treatment of parenteral nutrition-associated liver disease. Pediatrics 2008, 121, e678-e686.

71. Cowan, E.; Nandivada, P.; Puder, M. Fish oil-based lipid emulsion in the treatment of parenteral nutrition-associated liver disease. Curr. Opin. Pediatr. 2013, 25, 193-200.

72. De Meijer, V.E.; Gura, K.M.; Meisel, J.A.; Le, H.D.; Puder, M. Parenteral fish oil monotherapy in the management of patients with parenteral nutrition-associated liver disease. Arch. Sur. 2010, $145,547-551$.

73. Turner, J.M.; Field, C.J.; Goruk, S.; Wizzard, P.; Dicken, B.J.; Bruce, A.; Wales, P.W. Platelet Arachidonic Acid Deficiency May Contribute to Abnormal Platelet Function During Parenteral Fish Oil Monotherapy in a Piglet Model. JPEN J. Parenter. Enter. Nutr. 2015, doi:10.1177/0148607114568670.

74. Ng, K.; Stoll, B.; Chacko, S.; Saenz de Pipaon, M.; Lauridsen, C.; Gray, M.; Squires, E.J.; Marini, J.; Zamora, I.J.; Olutoye, O.O. Vitamin E in New-Generation Lipid Emulsions Protects Against Parenteral Nutrition-Associated Liver Disease in Parenteral Nutrition-Fed Preterm Pigs. JPEN J. Parenter. Enter. Nutr. 2015, doi:10.1177/0148607114567900.

75. Kosters, A.; Karpen, S.J. The role of inflammation in cholestasis: Clinical and basic aspects. Semin. Liver Dis. 2010, 30, 186-194. 
76. Colomb, V.; Jobert-Giraud, A.; Lacaille, F.; Goulet, O.; Fournet, J.C.; Ricour, C. Role of lipid emulsions in cholestasis associated with long-term parenteral nutrition in children. JPEN J. Parenter. Enter. Nutr. 2000, 24, 345-350.

77. Josephson, J.; Turner, J.M.; Field, C.J.; Wizzard, P.R.; Nation, P.N.; Sergi, C.; Ball, R.O.; Pencharz, P.B.; Wales, P.W. Parenteral Soy Oil and Fish Oil Emulsions: Impact of Dose Restriction on Bile Flow and Brain Size of Parenteral Nutrition-Fed Neonatal Piglets. JPEN J. Parenter. Enter. Nutr. 2014, doi:10.1177/0148607114556494.

78. Nghiem-Rao, T.H.; Tunc, I.; Mavis, A.M.; Cao, Y.; Polzin, E.M.; Firary, M.F.; Wang, X.; Simpson, P.M.; Patel, S.B. Kinetics of phytosterol metabolism in neonates receiving parenteral nutrition. Pediatric Res. 2015, doi:10.1038/pr.2015.78.

79. El Kasmi, K.C.; Anderson, A.L.; Devereaux, M.W.; Vue1, P.M.; Zhang, W.J.; Setchell, K.D.R.; Karpen, S.J.; Sokol1, R.J. Phytosterols promote liver injury and Kupffer cell activation in parenteral nutrition-associated liver disease. Sci. Transl. Med. 2013, 5, 206 ra137.

80. El Kasmi K.C.; Anderson, A.L.; Devereaux, M.W.; Fillon, S.A.; Harris, J.K.; Lovell, M.A.; Finegold, M.J.; Sokol, R.J. Toll-like receptor 4-dependent Kupffer cell activation and liver injury in a novel mouse model of parenteral nutrition and intestinal injury. Hepatology 2012, 55, $1518-1528$.

81. Lauriti, G.; Zani, A.; Aufieri, R.; Cananzi, M.; Chiesa, P.L.; Eaton, S.; Pierro, A. Incidence, prevention, and treatment of parenteral nutrition-associated cholestasis and intestinal failure-associated liver disease in infants and children: A systematic review. JPEN J. Parenter. Enter. Nutr. 2014, 38, 70-85.

82. Carter, B.A.; Taylor, O.A.; Prendergast, D.R.; Zimmerman, T.L.; Von Furstenberg, R.; Moore, D.D.; Karpen, S.J. Stigmasterol, a soy lipid-derived phytosterol, is an antagonist of the bile acid nuclear receptor FXR. Pediatric research 2007, 62, 301-306.

83. Eloranta, J.J.; Kullak-Ublick, G.A. The role of FXR in disorders of bile acid homeostasis. Physiology 2008, 23, 286-295.

84. Lam, H.S.; Tam, Y.H.; Poon, T.C.; Cheung, H.M.; Yu, X.; Chan, B.P.; Lee, K.H.; Lee, B.S.; $\mathrm{Ng}$, P.C. A double-blind randomised controlled trial of fish oil-based versus soy-based lipid preparations in the treatment of infants with parenteral nutrition-associated cholestasis. Neonatology 2014, 105, 290-296.

85. Cober, M.P.; Teitelbaum, D.H. Prevention of parenteral nutrition-associated liver disease: Lipid minimization. Curr. Opin. Organ Transplant. 2010, 15, 330-333.

86. Cober, M.P.; Killu, G.; Brattain, A.; Welch, K.B.; Kunisaki, S.M.; Teitelbaum, D.H. Intravenous fat emulsions reduction for patients with parenteral nutrition-associated liver disease. J. Pediatr. 2012, 160, 421-427.

87. Nandivada, P.; Carlson, S.J.; Chang, M.I.; Cowan, E.; Gura, K.M.; Puder, M. Treatment of parenteral nutrition-associated liver disease: The role of lipid emulsions. Adv. Nutr. 2013, 4, 711-777.

88. Singh, M. Essential fatty acids, DHA and human brain. Indian J. Pediatr. 2005, 72, 239-242.

89. Kruger, P.C.; Parsons, P.J.; Galusha, A.L.; Morrissette, M.; Recker, R.R.; Howard, L.J. Excessive aluminum accumulation in the bones of patients on long-term parenteral nutrition: 
Postmortem analysis by electrothermal atomic absorption spectrometry. JPEN J. Parenter. Enter. Nutr. 2014, 38, 728-735.

90. Courtney-Martin, G.; Kosar, C.; Campbell, A.; Avitzur, Y.; Wales, P.W.; Steinberg, K.; Harrison, D.; Chambers, K. Plasma Aluminum Concentrations in Pediatric Patients Receiving Long-Term Parenteral Nutrition. JPEN J. Parenter. Enter. Nutr. 2014, doi:10.1177/0148607114531046.

91. Moukarzel, A. Chromium in parenteral nutrition: Too little or too much? Gastroenterology 2009, 137, S18-S28.

92. Santos, D.; Batoreu, C.; Mateus, L.; Marreilha Dos Santos, A.P.; Aschner, M. Manganese in human parenteral nutrition: Considerations for toxicity and biomonitoring. Neurotoxicology 2014, 43, 36-45.

93. Kafritsa, Y.; Fell, J.; Long, S.; Bynevelt, M.; Taylor, W.; Milla, P. Long-term outcome of brain manganese deposition in patients on home parenteral nutrition. Arch. Dis. Child. 1998, 79, $263-265$.

94. Koseesirikul, P.; Chotinaruemol, S.; Ukarapol, N. Incidence and risk factors of parenteral nutrition-associated liver disease in newborn infants. Pediatr. Int. 2012,54, 434-436.

95. Li, S.J.; Nussbaum, M.S.; McFadden, D.W.; Gapen, C.L.; Dayal, R.; Fischer, J.E. Addition of glucagon to total parenteral nutrition (TPN) prevents hepatic steatosis in rats. Surgery 1988, 104, $350-357$.

96. Wang, H.; Khaoustov, V.I.; Krishnan, B.; Cai, W.; Stoll, B.; Burrin, D.G.; Yoffe, B. Total parenteral nutrition induces liver steatosis and apoptosis in neonatal piglets. J. Nutr. 2006, $136,2547-2552$.

97. Li, S.J.; Nussbaum, M.S.; McFadden, D.W.; Dayal, R.; Fischer, J.E. Reversal of hepatic steatosis in rats by addition of glucagon to total parenteral nutrition (TPN). J. Sur. Res. 1989, 46, 557-566.

98. Hsieh, M.H.; Pai, W.; Tseng, H.I.; Yang, S.N.; Lu, C.C.; Chen, H.L. Parenteral nutrition-associated cholestasis in premature babies: Risk factors and predictors. Pediatr. Neonatal. 2009, 50, 202-207.

99. Houten, S.M.; Auwerx, J. The enterohepatic nuclear receptors are major regulators of the enterohepatic circulation of bile salts. Ann. Med. 2004, 36, 482-491.

100. Shiao, T.; Iwahashi, M.; Fortune, J; Quattrochi, L.; Bowman, S.; Wick, M.; Qadri, I.; Simon, F.R. Structural and functional characterization of liver cell-specific activity of the human sodium/taurocholate cotransporter. Genomics 2000, 69, 203-213.

101. Chen, H.L.; Chen, H.L.; Liu, Y.J.; Feng, C.H.; Wu, C.Y.; Shyu, M.K.; Yuan, R.H.; Chang, M.H. Developmental expression of canalicular transporter genes in human liver. J. Hepatol. 2005, 43, 472-477.

102. Gao, B.; St Pierre, M.V.; Stieger, B.; Meier, P.J. Differential expression of bile salt and organic anion transporters in developing rat liver. J. Hepatol. 2004, 41, 201-208.

(C) 2015 by the authors; licensee MDPI, Basel, Switzerland. This article is an open access article distributed under the terms and conditions of the Creative Commons Attribution license (http://creativecommons.org/licenses/by/4.0/). 